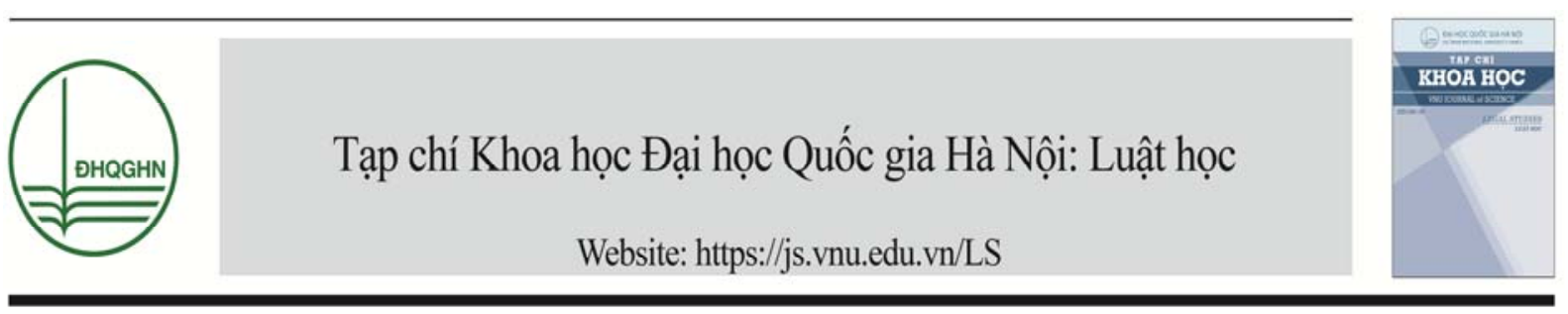

\title{
Giải quyết tranh chấp hợp đồng mua bán chung cư ở Việt Nam từ quan điểm bảo vệ người tiêu dùng
}

\author{
Phan Thị Thanh Thủy ${ }^{*}$ \\ Khoa Luật, Đại học Quốc gia Hà Nội, 144 Xuân Thủy, Cầu Giấy, Hà Nội, Việt Nam \\ Ngày nhận 20 tháng 11 năm 2018 \\ Chỉnh sửa ngày 17 tháng 12 năm 2018; Chấp nhận đăng ngày 24 tháng 12 năm 2018
}

\begin{abstract}
Tóm tắt: Các tranh chấp phát sinh từ hợp đồng mua bán nhà chung cư (HĐMBCC) ở Việt Nam đang ngày một gia tăng. Về bản chất, đây là các tranh chấp tiêu dùng phát sinh từ hợp đồng mua bán nhà ở hình thành trong tương lai nhưng lại chưa được các bên có liên quan và cơ quan nhà nước có thẩm quyền nhìn nhận thấu đáo. Do đó việc giải quyết tranh chấp chưa hiệu quả. Bài viết này sẽ tập trung vào làm rõ bản chất và các đặc điểm của tranh chấp phát sinh từ $\mathrm{HĐMBCC}$, các nguyên nhân dẫn đến tranh chấp và đưa ra những gợi mở về giải pháp nhằm giảm thiểu xung đột và giải quyết tranh chấp hiệu quả từ góc nhìn bảo vệ người tiêu dùng.

Tù khóa: Hợp đồng mua bán nhà chung cư, nhà ở hình thành trong tương lai, tranh chấp chung cư, tranh chấp tiêu dùng.
\end{abstract}

\section{1. Đề dẫn}

Từ đầu năm 2000 đến nay, do tốc độ đô thị hóa gia tăng mạnh mẽ ở các đô thị lớn, hàng loạt nhà chung cư được xây dựng ồ ạt để đáp ứng nhu cầu nhà ở cho người dân thành phố khi quỹ đất ở ngày càng hẹp lại. Các tranh chấp giữa người bán - các chủ đầu tư $(\mathrm{CĐT)} \mathrm{và}$ người mua trong quá trình thực hiện HĐMBCC cũng bùng phát mạnh mẽ về cả số lượng lẫn tính phức tạp [1]. Sự xung đột lợi ích giữa hai bên do không được nhìn nhận và giải quyết thấu đáo bởi các bên có liên quan và cơ quan nhà nước có thẩm quyền đã dẫn đến tranh chấp đối

\footnotetext{
*ĐT.: 84-983807028.

Email: thuyptt@vnu.edu.vn.

https://doi.org/10.25073/2588-1167/vnuls.4184
}

đầu gay gắt, và gây ra nhiều hệ lụy tiêu cực đối với đời sống và sinh hoạt của cư dân, ảnh hưởng đến sự ổn định trật tự - xã hội tại địa bàn có dự án.

Bài viết này sẽ tập trung vào làm rõ bản chất và các đặc điểm của tranh chấp phát sinh từ HĐMBCC, các nguyên nhân dẫn đến tranh chấp và đưa ra những gợi mở về giải pháp nhằm giảm thiểu xung đột và giải quyết tranh chấp hiệu quả từ góc nhìn bảo vệ người tiêu dùng (NTD). Về phạm vi, bài viết chỉ giới hạn trong các tranh chấp phát sinh từ $\mathrm{HĐMBCC}$ giữa $\mathrm{CĐT}$ và người mua thuộc các dự án xây dựng và kinh doanh chung cư thương mại, không đề cập đến loại hình chung cư do cá nhân/ hộ gia đình tự xây dựng để kinh doanh chỗ ở. Bài viết cũng không mở rộng đến các 
tranh chấp phát sinh trong quá trình quản lí và sử dụng chung cư ở giai đoạn hậu mãi.

\section{Khái quát về họ̣p đồng mua bán chung cư}

HĐMBCC được kí kết giữa người bán CĐT- với người mua (khách hàng). Theo đó CĐT thu được một khoản tiền nhất định và chuyển giao quyền sở hữu căn hộ cho người mua. Ngược lại, người mua trả tiền và trở thành chủ sở hữu căn hộ (chủ hộ).

Bên bán - CĐT: phải là doanh nghiệp hoặc hợp tác xã và đáp ứng các điều kiện đặc biệt để kinh doanh trong lĩnh vực xây dựng và kinh doanh bất động sản theo yêu cầu của Luật Xây dựng 2014 và Luật Kinh doanh bất động sản 2014 (Luật KDBĐS).

Ngườ mua/chủ hộ hoặc ngườ sủ dụng hợp pháp căn hộ: chính là "người tiêu dùng" (NTD) theo quan niệm tại Khoản 1 Điều 3 Luật Bảo vệ quyền lợi NTD (Luật BVNTD) 2010 ${ }^{i}$ và theo thông lệ quốc tế [2].

Đối tuợng của hợp đồng: chính là các căn hộ chung cư (CHCC) cụ thể trong tòa nhà chung cư thương mại thuộc về một dự án xây dựng và kinh doanh nhà chung cư đã được nhà nước cấp phép. Hiện tại, pháp luật chưa có định nghĩa về căn hộ chung cư nhưng từ định nghĩa nhà chung cư của Luật Nhà ở 2014: "Nhà chung cu là nhà có tù̀ 2 tầng trở lên, có nhiều căn hộ, có lối đi, cầu thang chung, có phần sở hưu riêng, phần sở hũu chung và hệ thống công trình ha tầng sủ dụng chung cho các hộ gia đình, cá nhân, tổ chức, bao gồm nhà chung cu được xây dưng với muc đỉch để ở và nhà chung cu được xây dưng có muc đỉch sủ dung hồn hợp để ở và kinh doanh" (Khoản 3 Điều 3), có thể hiểu rằng $\mathrm{CHCC}$ là nhũng diện tích để ở độc lập nằm trong nhà chung cu, thuộc sở hũu riêng của người mua.

\footnotetext{
${ }^{1}$ Theo Khoản 1 Điều 3 Luật BVNT 2010: "Người tiêu dùng là người mua, sử dụng hàng hóa, dịch vụ cho mục đích tiêu dùng, sinh hoạt của cá nhân, gia đình, tổ chức".
}

Từ quy định của pháp luật có thể thấy đối tượng của HĐMBCC có những đặc điểm khác với những hợp đồng mua bán hàng hóa khác đó là:

Thú nhất, các $\mathrm{CHCC}$, là nhà ở được sản xuất hàng loạt trong nền công nghiệp, luôn gắn với một tòa nhà chung cư và một dự án xây dựng, kinh doanh nhà chung cư cụ thể của CĐT, do cơ quan nhà nước có thẩm quyền phê duyệt và cho phép thực hiện dưới sự điều chỉnh của nhiều luật chuyên ngành như Luật Xây dựng 2014, Luật Nhà ở 2014, Luật Kinh doanh bất động sản (KDBĐS) 2014.

Thư hai, CHCC được pháp luật cho phép đưa vào giao dịch kinh doanh ngay từ khi còn đang trong quá trình xây dựng, chưa được nghiệm thu và đưa vào sử dụng, với tính cách "nhà ở hình thành trong tương lai" (off-the-plan house), theo quy định tại Khoản 19 Điều 3 của Luật nhà ở 2014 và Khoản 4, Điều 3 Luật KDBĐS 2014.

Bản chất và đặc điểm của hợp đồng mua bán căn hộ chung $\mathrm{cu}$

Về bản chất hợp HĐMBCC là hợp đồng mua bán nhà ở hình thành trong tương lai (Presale house contract) với những đặc trưng nổi bật như sau:

i) HĐMBCC luôn được thiết kế dưới dạng hợp đồng mẫu (Stardard form contract hoặc Contract of adherence) do bên bán (CĐT), tự soạn thảo, bên mua khi đồng ý giao kết hợp đồng phải chấp thuận toàn bộ các điều kiện mà bên bán đưa ra. Cách thức giao dịch này mặc dù có tính thúc đẩy thị trường, thuận lợi cho bên bán khi giao dịch những đối tượng là hàng hóa có cùng tính chất là các $\mathrm{CHCC}$ trong cùng dự án và những điều kiện mua bán tương tự, nhưng có thể không có lợi cho NTD bởi lẽ trong một hợp đồng theo mẫu, bên bán với lợi thế tự nhiên của bên soạn thảo, sẽ tìm cách hạ thấp trách nhiệm của mình với người mua trong các điều khoản của hợp đồng [3].

ii) Người mua kí kết HĐMBCC chủ yếu dựa vào các thông tin mà $\mathrm{CĐT}$ cung cấp và khó có điều kiện để kiểm chứng. Về lí luận, tính bất cân xứng về thông tin (Asymestric information) 
là đặc tính cơ bản của loại hợp đồng này. Đây cũng là thách thức lớn nhất ảnh hưởng đến kết quả thực hiện hợp đồng [4].

iii) Quyền lợi của người mua phụ thuộc rất nhiều vào năng lực thực hiện dự án và mức độ tôn trọng cam kết của CĐT. Vì vậy, loại hợp đồng này có khả năng phát sinh nhiều rủi ro, chẳng hạn như dự án có sai phạm, $\mathrm{CĐT} \mathrm{hoàn}$ thành chậm tiến độ, chất lượng công trình không đúng cam kết...[5, 6]

iv) $\mathrm{HĐMBCC} \mathrm{có} \mathrm{hình} \mathrm{thức} \mathrm{và} \mathrm{nội} \mathrm{dung}$ phức tạp, do nhiều đạo luật, bộ luật cùng tham gia điều chỉnh. Luật KDBĐS 2014 quy định việc mua bán nhà, công trình xây dựng phải kèm theo hồ sơ về nhà, công trình xây dựng (Khoản 4, Điều 19), bởi vậy HĐMBCC thực chất là một bộ hợp đồng dưới hình thức văn bản bao gồm 02 loại tài liệu: (1) Hồ sơ pháp lí dự án nhà chung cư và (2) Bản hợp đồng mua bán $\mathrm{CHCC}$.

Hồ so pháp lí dư án nhà chung cu: là tập hợp các giây tờ pháp lí phản ánh, quy trình thủ tục dự án được lập, thẩm định, phê duyệt đầu tư, thi công và kinh doanh. Các thông tin phải công khai tới người mua bao gồm: loại bất động sản, vị trí bất động sản, quy hoạch có liên quan, quy mô của bất động sản, đặc điểm, tính chất, công năng sử dụng, chất lượng của bất động sản; thông tin về từng loại mục đích sử dụng và phần diện tích sử dụng chung đối với bất động sản là tòa nhà hỗn hợp nhiều mục đích sử dụng, thực trạng các công trình hạ tầng, dịch vụ liên quan đến bất động sản (Khoản 1, Điều 6, Luật KDBĐS).

Bản hợp đồng mua bán căn hộ chung cu: chỉ quy định những nội dung cơ bản như bên bán, bên mua, mô tả căn hộ, giá cả phương thức thanh toán, quyền và nghĩa vụ của các bên, phương án giải quyết tranh chấp, hiệu lực của hợp đồng (Điều 121 Luật Nhà ở 2014). Điều đặc biệt là bản hợp đồng này phải được giải thich trong bối cảnh của hồ sơ dư án chung cu.

(v) Để hạn chế các rủi ro có thể xảy ra cho người mua, pháp luật đưa ra rất nhiều ràng buộc với các CTĐ trong các đạo luật trực tiếp liền quan. Chẳng hạn, Luật xây dựng 2014 yêu cầu
CĐT phải là thương nhân được cấp phép xây dựng, kinh doanh BĐS (Điều 4), Luật KDBĐS đưa ra rất nhiều điều kiện đối với bền bán như công khai giá cả và thanh toán nhiều lần theo tiến độ công trình (Điều 55, 57), bắt buộc $\mathrm{CĐT}$ có bảo lãnh ngân hàng với hợp đồng $\mathrm{MBCC}$ (Điều 56).

\section{Các tranh chấp điển hình phát sinh từ hợp đồng mua bán nhà chung cư, đặc điểm và nguyên nhân}

\section{* Các nhóm tranh chấp điển hình}

Xuất phát từ bản chất và đặc điểm của HĐMBCC, có thể chia các tranh chấp thành ba nhóm cơ bản như sau:

Nhóm tranh chấp phát sinh do CĐT vi phạm pháp luật, bao gồm các tranh chấp phổ biến như CĐT cung cấp thông tin gian dối, xây dựng không phép [7], vi phạm an toàn phòng cháy [8], người mua không làm được thủ tục sở hữu nhà ở do CĐT chưa giải chấp dự án khi mở bán [9].

Nhóm tranh chấp phát sinh do CĐT vi phạm các cam kết trong dụ án đã được phê duyệt và mở bán, bao gồm tự ý thay đổi thiết kế hạ tầng, hạng mục công trình... để tăng thu lợi nhuận. Phổ biến nhất là $\mathrm{CĐT} \mathrm{tự} \mathrm{ý} \mathrm{bỏ} \mathrm{các} \mathrm{công}$ trình phúc lợi công cộng để xây thêm cao ốc nhà văn phòng, trung tâm thương mại [10]. Ngoài ra, còn tự ý thay đổi cấu trúc và công năng của tòa nhà, thu hẹp các diện tích sở hữu chung như hành lang, cầu thang bộ gây bất lợi cho người mua [11], xây thêm tầng để tăng số lượng căn hộ và tăng diện tích sở hữu riêng của CĐT trong tòa nhà [12].

Nhóm tranh chấp do CĐT vi phạm các thỏa thuận đã ghi nhận trong hợp đồng mua bán CHCC. Điển hình là tranh chấp do CĐT bàn giao căn hộ không đúng thời hạn [13] tranh chấp do căn hộ không đạt yêu cầu về thiết kế và chất lượng như cam kết, thiếu hoặc thừa diện tích, nội thất không đúng vật liệu, chủng loại so với như mô tả trong hợp đồng [12].

Điều đáng lưu ý là không phải sai phạm nào cũng có thể phát hiện ngay tại thời điểm bàn 
giao. Có những vấn đề về chất lượng kém của công trình, người mua chỉ phát hiện ra trong quá trình sử dụng sau này. Điều này làm cho việc khiếu nại của người mua đối với $\mathrm{CĐT}$ càng thêm khó khăn.

\section{* Đặc điểm chung của tranh chấp hợp đồng mua bán chung $\mathrm{cu}$}

Thư nhất, các tranh chấp phát sinh tì hợp đồng $M B C C$ về bản chất pháp lí và thuoong mại là tranh chấp tiêu dùng, phát sinh trong và sau hơp đồng mua bán nhà ở hình thành trong twơng lai. Khi tranh chấp xảy ra khả năng tiếp cận và kiểm chứng các thông tin liên quan để chứng minh thiệt hại của NTD là rất hạn chế.

Thư hai, phần lớn tranh chấp MBCC mang tính tập thể. Những người mua/chủ hộ/người sử dụng hợp pháp CHCC trong cùng tòa nhà, cụm nhà chung cư của cùng một dự án thường có những khiếu nại, khởi kiện có tính chất tương tự về tính chất và nội dung pháp lí đối với $\mathrm{CĐT}$ như đã đề cập đến trong ba nhóm tranh chấp điển hình đã phân tích ở trên.

\section{* Các nguyên nhân dẫn đến tranh chấp}

Thư nhất, CĐT cố tình vi phạm các nguyên tắc, các nghĩa vụ của thương nhân KDBĐS và vi phạm quyền, lợi ích hợp pháp của NTD. Cụ thể vi phạm các nghĩa vụ, trách nhiệm của CĐT quy định tại Luật Xây dựng 2014 và Nghị định số $59 / 2015 / \mathrm{NĐ}-\mathrm{CP}$, vi phạm các điều cấm về "gian lận, lừa dối trong kinh doanh bất động sản" quy định tại Điều 13 và Khoản 4 Điều 8 Luật KDBĐS, vi phạm nghĩa vụ giao hàng đúng đối tượng, đúng chất lượng, đúng thời han và giá cả thỏa thuận quy định tại Khoản 6 Điều 8 của Luật BVNTD 2010, vi phạm các điều cấm tại Khoản 5 và 6 Điều 6 Luật Nhà ở 2014, vi phạm quyền được thông tin đầy đủ chính xác về hàng hóa của NTD quy định tại khoản 2 Điều 8 Luật BVNTD 2010 bằng các hành vi che dấu hoặc công bố một cách mập mờ các thông tin không có lợi cho dự án để thu hút NTD mua căn hộ, lừa dối NTD để bán nhà không phép, tự ý thay đổi dự án...
Thú hai, bản thân NTD khi mua CHCC đã không tìm hiểu kĩ lưỡng các thông tin pháp lí về dự án hoặc không hiểu hết các điều khoản của hợp đồng như đối tượng hợp đồng, giá cả, điều kiện giao dịch... Có một thực tế đáng chú ý là người mua thường không tự tìm hiểu kĩ càng các thông tin về dự án trong hồ sơ pháp lí, mà chủ yếu hình dung qua các tài liệu giới thiệu, quảng cáo do $\mathrm{CĐT}$ phát hành. Lợi dụng sự cả tin của khách hàng, các $\mathrm{CĐT}$ có thể đưa ra các thông tin không chính xác theo hướng có lợi để thúc đẩy việc mua bán giao dịch. Trường hợp xung đột giữa các chủ hộ và $\mathrm{CĐT} \mathrm{Home} \mathrm{City} \mathrm{do}$ sau khi mua nhà họ mới vỡ lẽ dự án không có lối đi ra phố Trung Kính như quảng cáo của $\mathrm{CĐT}$ mà chỉ có một lối đi nhỏ ở đường Nguyễn Chánh, là ví dụ điển hình [14].

Thư $b a$, có những tranh chấp xảy ra do các quy định của pháp luật về mua bán $\mathrm{CHCC}$ không đồng bộ, không phù hợp thực tiễn, các tiêu chuẩn kĩ thuật do cơ quan chức năng đưa ra trái ngược nhau khiến CĐT dễ dàng lựa chọn điểm yếu này để đưa ra các điều khoản giao dịch có lợi cho mình và gây thiệt hại cho NTD. Điển hình là vụ người mua kiện $\mathrm{CĐT}$ Keangnam ra tòa về việc đo sai, tính cả hộp kĩ thuật vào diện tích căn hộ, trái với Thông tư 01/2009/TT-BXD ngày 25 tháng 02 năm 2009. Trong khi đó $\mathrm{CĐT} \mathrm{lại} \mathrm{cho} \mathrm{rằng} \mathrm{công} \mathrm{ty} \mathrm{này} \mathrm{vận}$ dụng cách tính diện tích căn hộ thông thủy, bao gồm cả diện tích chung theo Thông tư 16/2010/ TT-BXD ban hành ngày 1/9/2010 [15]. Mặc dù Thông tư 16 đã bị Bộ Tư pháp kết luận chứa nhiều quy định không phù hợp, xâm phạm quyền lợi NTD và đã phải sửa đồi bằng Thông tư 03/2014/TT-BXD nhưng văn bản này đã gây ra rất nhiều hậu quả pháp lí tiêu cực.

Cuối cùng, tranh chấp chung cư còn phát sinh do các quyết định không phù hợp, thiếu minh bạch của cơ quan quản lí nhà nước. Nhiều trường hợp cơ quan chức năng chấp thuận các yêu cầu của $\mathrm{CĐT} \mathrm{về} \mathrm{điều} \mathrm{chỉnh} \mathrm{dự} \mathrm{án,} \mathrm{thay} \mathrm{đổi}$ thiết kế, công năng tòa nhà đối với các dự án đã được phê duyệt và triển khai bán trên thị trường, nhưng lại không kiểm tra sự đồng thuận của người mua đối với các thay đổi này. Điều này đã tạo điều kiện cho $\mathrm{CĐT}$ vi phạm nguyên 
tắc tự nguyện, thỏa thuận, trung thực giữa người bán và người mua, ảnh hưởng đến lợi ích NTD. Trường hợp CĐT khu đô thị Ngoại giao đoàn thay đổi thiết kế khi dự án đã được bán rộng rãi, gây bức xúc cho người mua, dẫn đến tranh chấp gay gắt là minh chứng của tình trạng thiếu trách nhiệm của một số cơ quan nhà nước có thẩm quyền [16]. Các quyết định thiếu minh bạch này đã xâm phạm quyền của NTD quy định tại Điều 8 Luật BVNTD, vi phạm nghĩa vụ của các cơ quan quản lí nhà nước quy định tại điều 77, 78 Luật KDBĐS.

\section{Các phương thức giải quyết tranh chấp nhà chung cư hiện hành}

\subsection{Phuoong thức giải quyết tranh chấp thay thế}

\section{* Phuong thúc thuoong luoong}

Theo cách này thường những người mua/chủ hộ tự tập hợp lại để bày tỏ khiếu nại, yêu cầu giải quyết mâu thuẫn với $\mathrm{CĐT}$. Trường hợp nhà chung cư đã được bàn giao và đưa vào sử dụng, các chủ hộ hoặc thông qua tổ dân phố trong trường hợp Ban quản trị tòa nhà/ cụm nhà, chưa được thành lập hoặc ủy quyền cho Ban quản trị đứng ra khiếu nại $\mathrm{C} Đ T$ và đại diện giải quyết tranh chấp.

Trong các cuộc đàm phán để giải quyết khiếu nại, tranh chấp, CĐT thường lợi dụng sự yếu thế của NTD trong việc thiếu thông tin chứng minh thiệt hại để cố tình trì hoãn đối thoại hoặc không đưa ra phương án giải quyết. Bởi lí do này, việc đàm phán với $\mathrm{CĐT}$ thường nhanh chóng diễn biến thành đối đầu gay gắt giữa hai bên ảnh hưởng nghiêm trọng tới đời sống cư dân và trật tự trị an, văn minh đô thị.

\section{* Phuoong thức hòa giải}

Hòa giải được coi là phương pháp ưu tiên hàng đầu khi giải quyết tranh chấp tư liên quan đến đất đai nhà ở, tranh chấp tiêu dùng, bao gồm cả tranh chấp MBCC. Tuy nhiên, cho đến nay cả Điều 177 Luật Nhà ở 2014 và Điều 43 của Thông tư số 02/2016/TT-BXD ngày $15 / 2 / 2016$ về quản lí và sử dụng nhà chung cư đều không có giải thích rõ ràng đây là loại hòa giải thương mại độc lập hay hòa giải cơ sở có sự tham gia của chính quyền địa phương. Do không có cơ chế rõ ràng nên phương thức hòa giải cũng kém hiệu quả, ít được thực thi trên thực tế.

\section{*Phuong thức trọng tài thuoong mại}

Mặc dù tranh chấp chung cư hoàn toàn có thể giải quyết bằng trọng tài, tuy nhiên trên thực tế, hầu hết điều khoản giải quyết tranh chấp trong các HĐMBCC đều lựa chọn phương thức tòa án trong trường hợp thương lượng không thành. Có lẽ các CĐT khi soạn thảo điều khoản giải quyết tranh chấp trong hợp đồng mua bán CHCC đều được tư vấn về quyền từ bỏ điều khoản trọng tài của NTD quy định tại Điều 17 Luật Trọng tài Thương mại 2010 và Điều 38 Luật BVNTD. Việc lựa chọn tòa án là phương án giúp cho CĐT khỏi băn khoăn về việc phải xử lí tranh chấp về lựa chọn cơ quan tài phán có thể xảy ra.

\subsection{Giải quyết tranh chấp chung cu bằng biện pháp hành chính}

* Giải quyết tranh chấp thông qua Ủy ban nhân dân các cấp

Hiện tại Luật Nhà ở không quy định trách nhiệm của Ủy ban nhân dân (UBND) các cấp trong tham gia giải quyết tranh chấp phát sinh từ $\mathrm{HĐMBCC} \mathrm{thương} \mathrm{mại,} \mathrm{mà} \mathrm{chỉ} \mathrm{quy} \mathrm{định}$ thẩm quyền của UBND cấp tỉnh trong giải quyết các tranh chấp nhà chung cư thuộc sở hữu Nhà nước, tranh chấp về kinh phí quản lí vận hành nhà chung cư, về sở hữu chung, riêng (Khoản 2 và 3 Điều 177).

Khoảng trống pháp luật này vô hình chung hạ thấp vai trò và chức năng quản lí Nhà nước của UBND các cấp. Các dự án nhà chung cư là nơi cư trú tập trung của các cộng đồng dân cư lớn, mật độ cao và là một phần của đơn vị hành chính cấp cơ sở. Do vậy, cả CĐT và cư dân đều phải có mối liên hệ chặt chẽ với chính quyền sở tại trong quan hệ quản lí nhà nước và quan hệ xã hội. Có một thực tế là nhiều tranh chấp chung cư rất cần đến sự tham gia tích cực của chính quyền địa phương, đặc biệt là các tranh chấp liên quan đến các sai phạm của $\mathrm{C} Đ \mathrm{~T}$ trong 
thực hiện dự án đã được phê duyệt. Trường hợp tranh chấp đường đi giữa cư dân hai khu đô thị Goldmark City với Vinaconex 7, chỉ khi UBND thành phố Hà Nội chỉ đạo UBND quận Bắc Từ Liêm công bố công khai quy hoạch khu đô thị và khẳng định con đường mà CĐT Goldmark City tuyên bố là đường nội bộ chính là đường đi được quy hoạch chung cho cả hai dự án, căng thẳng giữa hai bên mới giảm xuống. Cư dân Goldmark City mới vỡ lẽ $\mathrm{CĐT} \mathrm{đã} \mathrm{cung} \mathrm{cấp} \mathrm{thông} \mathrm{tin} \mathrm{sai} \mathrm{lệch}$ về dự án trong quá trình rao bán căn hộ [17]. Tương tự, UBND quận Cầu Giấy cũng phải tham gia vào tìm kiếm phương án tạo dựng lối đi mới cho cư dân Home City để đảm bảo sinh hoạt thuận tiện, giảm bức xúc cho cộng đồng cư dân trên địa bàn mình quản lí [14].

* Giải quyết tranh chấp chung cu thông qua co quan bảo vệ nguời tiêu dùng

Ở nước ta, Phòng BVNTD trực thuộc Cục

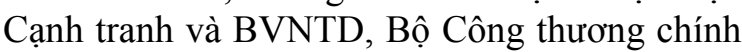
là cơ quan $\mathrm{BVNTD}$ cấp quốc gia vừa thực hiện chức năng giám sát các hợp đồng mẫu mua bán CHCC vừa trực tiếp tiếp nhận khiếu nại về các vi phạm hợp đồng và tiến hành hòa giải mâu thuẫn giữa hai bên. Trong trường hợp hòa giải không có kết quả, cơ quan này sẽ báo cáo các sai phạm của $\mathrm{CĐT} \mathrm{cho} \mathrm{các} \mathrm{cơ} \mathrm{quan} \mathrm{chức} \mathrm{năng}$ và kiến nghị xử phát hành chính theo quy định của pháp luật [18].

Mặc dù vai trò hiện tại của Phòng BVNTD là rất đáng khuyến khích, tuy nhiên cơ quan này không có thực quyền để giải quyết triệt để tranh chấp và cũng không được quyền áp dụng các chế tài hành chính đối với sai phạm của $\mathrm{CĐT}$. Trong trường hợp CĐT không nhận sai phạm, không chịu đưa ra biện pháp khắc phục thiệt hại cho người mua căn hộ, giải pháp hành chính này cũng chỉ có tính chất nửa vời.

\subsection{Giải quyết tranh chấp chung cu bằng tòa án}

Mặc dù không nhiều vụ tranh chấp hợp đồng $\mathrm{MBCC}$ được khởi kiện và đưa ra tòa xét xử nhưng có lẽ đây là cách giải quyết triệt để nhất tạo ra những tiền lệ tốt để răn đe các $\mathrm{CĐT}$ cố tình vi phạm các thỏa thuận trong hợp đồng.
Bản án phúc thẩm tuyên ngày 3/12/2015 Tòa án Nhân dân thành phố Hà Nội buộc CĐT Keang Nam Vina phải hoàn trả toàn bộ số tiền mà người mua đã nộp để chấm dứt quá trình tranh chấp kéo dài từ năm 2012 nhưng đã bị CĐT từ chối xử lí và cơ quan chức năng không giải quyết được là một minh chứng rõ ràng về hiệu quả của giải quyết tranh chấp HĐMBCC bằng tòa án [19]. Tuy nhiên, trên thực tế, các vụ tranh chấp chung cư được đưa ra tòa án giải quyết không nhiều vì một số nguyên nhân sau:

Thư nhất, việc khởi kiện tại tòa đòi hỏi người khởi kiện, thường là người mua/ chủ hộ, phải dẫn ra các tài liệu, chứng cứ có liên quan đến hồ sơ pháp lí dự án để chứng minh thiệt hại của mình do vi phạm của CĐT gây ra. Đa số các tài liệu này đều do phía $\mathrm{C} Đ \mathrm{~T}$ trực tiếp nắm giữ, chỉ giới thiệu một số thông tin cho người mua lúc chào hàng hoặc giao dịch. Việc người khởi kiện tiếp xúc với cơ quan nhà nước có thẩm quyền như UBND cấp tỉnh, sở xây dựng, sở kế hoạch đầu tư, UBND cấp huyện và các cơ quan chức năng khác đề nghị hỗ trợ tài liệu là khó có khả năng thực hiện vì tinh thần hỗ trợ người dân còn rất kém.

Thư hai, việc giải quyết tranh chấp chung cư tại tòa áp dụng thủ tục tố tụng dân sự thông thường nên thường cứng nhắc, thời gian xét xử kéo dài khiến việc đeo đuổi kiện tụng thêm khó khăn cho nguyên đơn. Thêm vào đó, do thiếu cơ chế khởi kiện tập thể, những người mua/chủ hộ trong cùng một tòa nhà, cụm nhà có cùng mâu thuẫn lợi ích với $\mathrm{CĐT}$ vẫn phải kiện thành các vụ việc riêng lẻ mà không được liên kết với nhau để khởi kiện $\mathrm{CĐT}$ trong cùng một vụ việc. Điều này dẫn đến sự tốn kém công sức và chi phí cho quy trình tố tụng của cả tòa án lẫn người khởi kiện, chưa kể nỗi e ngại của họ khi phải đối mặt với $\mathrm{CĐT} \mathrm{có} \mathrm{tiềm} \mathrm{lực} \mathrm{tài} \mathrm{chính} \mathrm{và}$ có khả năng chi phối các mối quan hệ xã hội.

\section{Bình luận và một số gọii ý}

Rõ ràng tranh chấp $\mathrm{MBCC}$ ở các đô thị lớn Việt Nam những năm gần đây đã đến mức độ báo động, ngày càng lan rộng và gây nhiều hệ 
lụy xấu cho các bên và cho xã hội. Thực trạng này là do cơ chế giải quyết tranh chấp vẫn còn tản mạn, thiếu liên kết với nhau, nhiều cách thức, biện pháp được sử dụng vẫn không hiệu quả.

Tranh chấp phát sinh từ HĐMBCC mang tính chất pháp lí rất phức tạp, bởi lẽ vừa là tranh chấp tiêu dùng, vừa là tranh chấp về nhà ở hình thành trong tương lai, nhưng dường như các nhà làm luật và các cơ quan chức năng của Nhà nước chưa có một chính sách chung nhất quán, thấu đáo về đường lối giải quyết loại tranh chấp này. Các quy định của pháp luật hiện hành còn nặng về khía cạnh giải quyết tranh chấp bất động sản, chưa thực sự quan tâm đến khía cạnh bảo vệ NTD để có những phản ứng thích hợp và giải quyết nhanh chóng hiệu quả.

Để giảm thiểu số lượng tranh chấp chung cư và các hậu quả tiêu cực về kinh tế -xã hội phải kết hợp nhiều giải pháp toàn diện, trong đó phải kể đến những giải pháp mang tính chất phòng ngừa và các giải pháp pháp lí đồng bộ, lâu dài:

\subsection{Giải pháp phòng ngùa, hạn chế tranh chấp}

* Về phía cơ quan quản lí nhà nước về dụ án nhà chung $\mathrm{cu}$

Cần tăng cường kiểm tra giám sát, xử phạt hành chính nghiêm minh, thích đáng đối với các CĐT không minh bạch thông tin về hồ sơ pháp lí dự án nhà chung cư với khách hàng. Đối với những trường hợp $\mathrm{CĐT}$ gian dối hoặc công bố mập mờ thông tin trong quá trình giao dịch nhằm trục lợi từ khách hàng, cần có chế tài xử phạt tiền thích đáng, yêu cẩu bồi thường thiệt hại cho khách hàng, thu hồi giấy phép xây dựng. Trường hợp gây hậu quả nghiêm trọng cần xử lí hình sự về gian lận kinh doanh. Thực trạng xử phạt hành chính hiện nay cho thấy các chế tài xử phạt còn nhẹ, $\mathrm{CĐT} \mathrm{sẵn} \mathrm{sàng} \mathrm{nộp} \mathrm{phạt}$ để duy trì dự án, công trình vi phạm kiếm lời [20]. Việc áp dụng các chế tài hành chính, hình sự nghiêm khắc sẽ có sức răn đe làm giảm vi phạm, bảo vệ NTD. Ngược lại, rất cần có chế tài hành chính, hình sự nghiêm khắc đối với những cá nhân đứng đầu cơ quan chức năng ra các quyết định thiếu trách nhiệm, trái luật gây thiệt hại nghiêm trọng cho NTD.
Pháp luật cần có quy định rõ ràng về vai trò tham gia bắt buộc UBND huyện, tỉnh trong hỗ trợ người dân trong các tranh chấp liên quan đến vi phạm thỏa thuận trong dự án đã được phê duyệt của CĐT chung cư. Hơn ai hết, các cơ quan này quản lí các thông tin về dự án, khi họ công bố quan điểm khách quan và đúng đắn về mâu thuẫn giữa $\mathrm{CĐT}$ và người mua/ chủ hộ, sẽ góp phần chỉ rõ đúng sai, giảm tải xung đột giữa các bên một cách nhanh chóng và đặc biệt là ổn định trật tự trị an khu vực. Trường hợp các bên thương lượng, hòa giải không thành, trong thời hạn nhất định, UBND cấp huyện có trách nhiệm yêu cầu $\mathrm{CĐT}$ cung cấp các thông tin có liên quan đến hợp đồng mua bán CHCC để người dân khởi kiện ra tòa dân sự.

* Về phía người mua: Cần nâng cao ý thức tự bảo vệ quyền lợi chính đáng của mình, chủ động tìm hiểu kĩ các thông tin pháp lí về dự án, các điều khoản về hợp đồng, yêu cầu $\mathrm{CĐT,}$ người bán công khai các loại tài liệu này. Trường hợp CĐT từ chối, phải báo đến cơ quan chức năng như sở xây dựng, Phòng BVNTD đề nghị làm rõ. Nếu có khả năng chi phí, nên thuê luật sư tư vấn khi giao dịch mua CHCC. Trong trường hợp có mâu thuẫn, tranh chấp xảy ra mà không được CĐT giải quyết thỏa đáng, cư dân cần phản ánh ngay với cơ quan chức năng và mạnh dạn khởi kiện ra tòa yêu cầu giải quyết.

\subsection{Gợi ý các giải pháp hoàn thiện pháp luật và nâng cao hiệu quả thục thi \\ * Ban hành Luật chung cu}

Việc ban hành một đạo luật về chung cư để điều chỉnh các quan hệ phát sinh trong quản lí, xây dựng và kinh doanh dự án nhà chung cư là điều hết sức cần thiết. Luật này sẽ chứa đựng các quy định có tính đồng bộ, chặt chẽ và cụ thể về các quy chuẩn về đầu tư xây dựng dự án, giao dịch mua bán $\mathrm{CHCC}$ cũng như các tiêu chuẩn kĩ thuật về cách tính toán các diện tích xây dựng, các quy định về phân định cụ thể rạch ròi sở hữu chung, riêng, về quản lí và vận hành nhà chung cư... để $\mathrm{CĐT}$, nhà môi giới giao dịch, công ty dịch vụ và khách hàng đều hiểu rõ và quản lí được các thông tin này. 


\section{* Bổ sung sứa đổi Bộ luật Tố tưng Dân sụ 2015 để công nhận khởi kiện tập thể}

Kiện tập thể - vụ kiện do nhiều người cùng đứng chung đơn kiện để kiện một người - là một trình tự tố tụng tư pháp đặc biệt được tòa án rất nhiều nước trên thế giới áp dụng để giải quyết tranh chấp tư trong đó có tranh chấp tiêu dùng. Ngay trong khối ASEAN, hiện tại đã có năm nước, thuộc nhóm có trình độ kinh tế xã hội vượt trội so với các nước còn lại bao gồm Singapore, Malaysia, Thailan, Indonesia và Phillipines đã áp dụng kiện tập thể để giải quyết các tranh chấp lao động, tranh chấp tiêu dùng và tranh chấp đất đai - môi trường.

Theo pháp luật của các nước công nhận kiện tập thể, về cơ bản, đều thống nhất bốn tiêu chí để được công nhận là vụ kiện tập thể bao gồm (1) Nhóm người tham gia khởi kiện lớn đến mức việc giải quyết các vụ kiện riêng rẽ là quá phức tạp và không thể thực hiện được, (2) Phải có những vấn đề pháp lí và thực tiễn chung cho cả nhóm, (3) Các yêu cầu hoặc lời biện hộ của người đại diện đứng ra khởi kiện phải phù hợp với lợi ích của nhóm người tham gia và (4) Người đại diện khởi kiện phải bảo vệ một cách thích hợp lợi ích của cả nhóm [21]. Như vậy, xét về tính chất pháp lí và cơ sở thực tế, các tranh chấp chung cư phát sinh từ hành vi vi phạm các cam kết trong hợp đồng của CĐT ở Việt Nam hiện nay đã đáp ứng đầy đủ các điều kiện của các vụ kiện tập thể theo thông lệ quốc tế và cần được thụ lí và giải quyết theo thủ tục tố tụng riêng để bảo đảm được giải quyết triệt để và bảo vệ lợi ích chính đáng của NTD.

Trong một số nghiên cứu trước đó, tác giả đã phân tích và nhận định rằng kiện tập thể trong tranh chấp tiêu dùng là xu hướng tất yếu trong một nền tư pháp hiện đại; loại tranh chấp này sẽ ngày càng gia tăng trong đời sống dân sự - thương mại. Việc Bộ luật Tố tụng dân sự (TTDS) 2015 không có quy định về trình tự TTDS đặc biệt cho kiện tập thể, mà chỉ quy định về thủ tục nhập các vụ án dân sự có trong trường hợp nhiều người cùng kiện một cá nhân hay tổ chức thành một vụ án để giải quyết (Khoản 1, Điều 42), đang làm cho quy trình TTDS và hệ thống tòa án của chúng ta lạc hậu so với thế giới và cả trong khu vực ASEAN, chưa kể trong bối cảnh hội nhập kinh tế thế giới và khu vực, thiếu hụt này còn đang tạo ra các rào cản tư pháp trong việc bảo vệ nền thương mại lành mạnh công bằng và bảo vệ các quyền lợi chính đáng của NTD $[21,22]$. Để khắc phục các hạn chế này, các nhà làm luật nên nhanh chóng tiếp cận các thông lệ quốc tế về kiện tập thể để nghiên cứu, học tập kinh nghiệm nhằm bổ sung khái niệm kiện tập thể, các điều kiện khởi kiện và quy trình, thủ tục giải quyết vụ kiện tập thể vào Bộ luật TTDS hiện hành để bảo đảm rằng tố tụng tòa án thực sự bảo vệ NTD và theo kịp các nền tư pháp hiện đại.

* Áp dụng tố tụng rút gon vào giải quyết tranh chấp chung $\mathrm{cu}$

Mặc dù từ 2010, Luật BVNTD đã có quy định việc áp dụng tố tụng rút gọn đối với các tranh chấp tiêu dùng có tính chất đơn giản với các vi phạm rõ ràng và giá trị tranh chấp dưới 100 triệu đồng, song suốt cả thời gian dài sau đó vẫn chưa thực thi được vì Bộ luật TTDS 2005 chưa có quy định này. Hiện tại, Điều 317 Bộ luật TTDS 2015 đã cu thể hóa các điều kiện để xét xử rút gọn bao gồm: (1) vụ án có tình tiết đơn giản, quan hệ pháp luật rõ ràng, đương sự đã thừa nhận nghĩa vụ; tài liệu, chứng cứ đầy đủ, bảo đảm đủ căn cứ để giải quyết vụ án và Tòa án không phải thu thập tài liệu, chứng cứ; (2) Các đương sự đều có địa chỉ nơi cư trú, trụ sở rõ ràng; (3) Không có đương sự cư trú ở nước ngoài, tài sản tranh chấp ở nước ngoài, trừ trường hợp đương sự ở nước ngoài và đương sự ở Việt Nam có thỏa thuận đề nghị Tòa án giải quyết theo thủ tục rút gọn hoặc các đương sự đã xuất trình được chứng cứ về quyền sở hữu hợp pháp tài sản và có thỏa thuận thống nhất về việc xử lí tài sản. Điều đặc biệt là Bộ luật TTDS không quy định về giới hạn giá trị tài sản tranh chấp như Luật BVNTD.

Uu điểm của tố tụng rút gọn là tiết kiệm nhân lực tiến hành tố tụng, tiết kiệm thời gian, chi phí cho đương sự trong tất cả các cấp xét xử. Dưới góc độ bảo vệ NTD, đây là quy trình tố tụng tiến bộ, đã được nhiều quốc gia trên thế giới áp dụng phổ biến để bảo vệ NTD yếu thế 
trong các tranh chấp với thương nhân [23]. Trong bối cảnh số lượng và độ phức tạp tranh chấp chung cư đang dâng cao, cần mạnh dạn áp dụng thủ tục rút gọn để giải quyết các tranh chấp phát sinh trong trường hợp các vi phạm của $\mathrm{CĐT} \mathrm{đã} \mathrm{rõ} \mathrm{ràng,} \mathrm{chẳng} \mathrm{hạn} \mathrm{giao} \mathrm{nhà} \mathrm{chậm}$ tiến độ, vi phạm các cam kết về kết cấu tòa nhà, về thiết kế, chất lượng nội thất của căn hộ.

Tăng cường vai trò bắt buộc của chính quyền địa phương trong giải quyết tranh chấp

Pháp luật cần có quy định rõ ràng về vai trò tham gia bắt buộc UBND huyện, tỉnh hỗ trợ người dân trong các tranh chấp liên quan đến vi phạm thỏa thuận trong dự án đã được phê duyệt của $\mathrm{CĐT}$ chung cư. Hơn ai hết, các cơ quan này quản lí các thông tin về dự án, khi họ công bố quan điểm khách quan và đúng đắn về mâu thuẫn giữa $\mathrm{CĐT}$ và người mua/ chủ hộ, sẽ góp phần chỉ rõ đúng sai, giảm tải xung đột giữa các bên một cách nhanh chóng và đặc biệt là ổn định trật tư trị an khu vực. Trường hợp các bên thương lượng, hòa giải không thành, trong thời hạn nhất định, UBND cấp huyện có trách nhiệm yều cầu CĐT cung cấp các thông tin có liên quan đến hợp đồng mua bán CHCC để người dân khởi kiện ra tòa dân sự.

\section{Tài liệu tham khảo}

[1] Theo số liệu của Bộ xây dựng, tính đến đầu tháng 6/2018 đã có khoảng 215 dự án có khiếu nại, tranh chấp trong đó có 108 dự án có tranh chấp giữa CĐT và người mua căn hộ; xem Hồng Khanh, 5 'điểm huyệt' của hàng trăm chung cư xảy ra tranh chấp, tại vietnamnet.vn/vn/bat-dong-san/bo-xaydung-bao-cao-chinh-phu-ve-tranh-chap-chung-cu455596.html\#inner-article (truy cập 27/10/2018).

[2] Phan Thị Thanh Thủy, Một số vấn đề pháp lí trong giải quyết tranh chấp giữa người tiêu dùng và bên cung cấp hàng hóa dịch vụ bằng phương thức thương thượng, Tạp chí Nhà nước và Pháp Luật. 343(11/2016); tr.54-55.

[3] Korobkin, R., Bounded Rationality, Standard Form Contracts, and Unconscionability,. University of Chicago Law Review (2003). Vol. 70 : Iss. 4, 1203-1295, xem tr. 1285-1288.

[4] Shmuel I. Bechern, Asymmetric Information inConsumer Contracts: The ChallengeThat Is Yet to Be Met, . American Business Law Journal,. Volume 45, Issue 4, 723-774, Winter 2008; tr. 727-728.

[5] British Columbia, C.-F.I.C.C., Alert: Risks Associated with the Assignment of "Pre-Sale" Contracts of Purchase and Sale, May 2008 tr.1-2. tại file:///E:/DESKTOP_Doc/Tranh\% $\% 20 \mathrm{ch} \% \mathrm{C} 3 \% \mathrm{~A} 2 \mathrm{p} \% 2$ 0chung $\% 20 \mathrm{c} \% \mathrm{C} 6 \% \overline{\mathrm{B}} 0 /$ risks-associated-assignmentof-presale-contracts.pdf (truy cập 20/11/2018 ).

[6] Nguyễn Đình Phong và Trần Thu Hương, Một số bất cập về hợp đồng mua bán nhà ở hình thành trong tương lai tại https://tapchitoaan.vn/baiviet/kinh-te/mot-so-bat-cap-ve-hop-dong-muaban-nha-o-hinh-thanh-trong-tuong-lai (truy cập 20/10/2018).

[7] Nguyễn Hà, Chung cư giữa thủ đô ở nhiều năm vẫn không được cấp sổ đỏ https://kinhdoanh.vnexpress.net/tin-tuc/bat-dongsan/chung-cu-giua-thu-do-o-nhieu-nam-vankhong-duoc-cap-so-do-3748992.html.(15/7/2018).

[8] Kiều Linh, Hà Nội công khai 91 chung cư, toà nhà vi phạm phòng cháy chữa cháy, tại http://vneconomy.vn/ha-noi-cong-khai-91-chungcu-toa-nha-vi-pham-phong-chay-chua-chay20180529121350006.htm (truy cập 11/10/2018).

[9] Nguyễn Hà, Khách mua nhà nên yêu cầu chủ đầu tư cung cấp hồ sơ giải chấp, tại https://kinhdoanh.vnexpress.net/tin-tuc/bat-dongsan/khach-mua-nha-nen-yeu-cau-chu-dau-tucung-cap-ho-so-giai-chap-3816224.html (truy cập 11/10/2018).

[10] Việt Dương, Cần xử nghiêm các chủ đầu tư tự ý thay đồi thiết kế dự án, tại https://tinnhanhchungkhoan.vn/bat-dong-san/canxu-nghiem-cac-chu-dau-tu-tu-y-thay-doi-thiet-kedu-an-191394.html (truy cập 10/11/2018).

[11] Minh Đỗ, Dự án D’. Capitale: Khách hàng và Chủ đầu tư chưa tìm được tiếng nói chung, https://www.nguoitieudung.com.vn/du-an-dcapitale-khach-hang-va-chu-dau-tu-chua-tim-duoctieng-noi-chung-d71052.html (truy cập 18/11/2018).

[12] Phương Dung, Mua nhà chung cư: Ngỡ ngàng chủ đầu tư tự ý thay đổi thiết kế, http://dantri.com.vn/kinh-doanh/mua-nha-chungcu-ngo-ngang-chu-dau-tu-tu-y-thay-doi-thiet-ke20170317151113834.htm (truy cập 16/10/2018).

[13] Ngọc Mai, Chủ đầu tư chậm tiến độ: Xử phạt hay buộc bồi thường? https://www.tienphong.vn/diaoc/chu-dau-tu-cham-tien-do-xu-phat-hay-buocboi-thuong-1150836.tpo (truy cập 10/10/2018).

[14] Hồng Khanh, Bài học đắt giá cho người mua nhà từ tranh chấp tại Home City http://vietnamnet.vn/vn/bat-dong-san/du-an/tranh- 
chap-tai-du-an-home-city-bai-hoc-dat-gia-chonguoi-mua-nha-360977.html (truy cập 13/03/2017).

[15] Việt Dũng, Cư dân Keangnam đòi chủ đầu tư tính đúng diện tích căn hộ, tại https://vnexpress.net/tintuc/phap-luat/cu-dan-keangnam-doi-chu-dau-tu-tinhdung-dien-tich-can-ho-3246513.html (16/8/2017).

[16] Ngọc Mai, Căng thẳng tại các chung cư cao cấp: Bức xúc vì chủ đầu tư bội tín, http://vietnamnet.vn/vn/bao-ve-nguoi-tieu-dung/bucxuc-vi-chu-dau-tu-boi-tin-422307.html (truy cập 16/8/2018).

[17] Nhân Hà, Phía sau những lùm xùm tranh chấp tại dự án Goldmark City, tại https://nhadautu.vn/phiasau-nhung-lum-xum-tranh-chap-tai-du-angoldmark-city-d9215.html (truy cập 8/7/2018).

[18] VCA, Hướng dẫn NTD khiếu nại tại http://www.vca.gov.vn/expage_bvntd.aspx?id=36\& Cate ID $=444$.

[19] Hoa Đỗ, Phúc thẩm vụ án Keangnam Vina bị khách hàng khởi kiện, http://phapluatxahoi.vn/phuc-tham-vu-an- keangnam-vina-bi-khach-hang-khoi-kien57675.html (truy cập 18/6/2018).

[20] P. Thảo, Rà lại quy định "phạt cho tồn tại" công trình xây sai phép, https://dantri.com.vn/diendan/ra-lai-quy-dinh-phat-cho-ton-tai-cong-trinhxay-sai-phep-1395180378.htm (truy cập 28/10/2018).

[21] Phan Thị Thanh Thủy, Kiện tập thể trong giải quyết tranh chấp tiêu dùng ở một số nước ASEAN và những gợi ý cho Việt Nam, Tạp chí Nhà nước và Pháp Luật,. . 1(357)/2018: p. 40-50.

[22] Phan Thị Thanh Thủy, Từ vụ kiện Apple làm chậm iPhone ở việt Nam, Bàn về xu hướng khởi kiện tập thể trong giải quyết tranh chấp tiêu dùng, . Tạp chí Khoa học Đại học Quốc gia Hà nội: Luật học Vol.34, No. 2, 2018, tr. 80-82.

[23] Hồ Nguyễn Quân, Một số vấn đề về thủ tục rút gọn trong Bộ luật TTDS năm 2015, tại http://moj.gov.vn/qt/tintuc/Pages/nghien-cuu-traodoi.aspx?ItemID $=2139$ ngày $04 / 05 / 2017$ (Truy cập 24/9/2018).

\title{
Settling Disputes Arising from Condominium Sale Contracts in Vietnam from the Perspective of Consumer Protection
}

\author{
Phan Thi Thanh Thuy \\ VNU School of Law, 144 Xuan Thuy, Cau Giay, Hanoi, Vietnam
}

\begin{abstract}
Disputes arising from the sale of condominiums are on the rise in Vietnam. In nature, these are consumer disputes occurring from the off-the-plan house purchase contracts that have not been fully recognized by the parties concerned and by the competent state authorities. Therefore, the resolutions of disputes are not operative enough. This article focuses on clarifying the legal nature and characteristics of the disputes arising from condominium sale contracts, the causes of the disputes, and suggests solutions to reduce conflicts and resolve disputes effectively from the perspective of consumer protection.
\end{abstract}

Keywords: Condominium sale contracts, off-the-plan houses, condominium dispute, consumer dispute. 